\title{
Fashion, Growth and Welfare: An Evolutionary Approach
}

\author{
Andreas Chai \\ Max Planck Institute of Evolutionary Economics, Jena, Germany. chai@ mpiew-jena.mpg.de \\ Peter Earl \\ School of Economics, University of Queensland, St Lucia, QLD 4071, Australia. \\ p.earl@economics.uq.edu.au \\ Jason Potts \\ School of Economics, University of Queensland, St Lucia, QLD 4071, Australia. \\ i.potts@economics.uq.edu.au (corresponding author)
}

\section{$1 \quad$ INTRODUCTION}

The task of this paper is to explore the interplay between fashion, consumer lifestyles and economic growth in the context of a world of technological change in which the menu of possibilities that consumers face is constantly changing and tending to increase in length. Our working definition of 'fashion' is simple, namely the tendency or behavioral norm of actors to adopt certain types or styles of customs or commodities nearly simultaneously, only to adopt a different type or style of custom or commodity in future periods. The demand spikes associated with fashion may pertain to newly introduced products or to products that have been around for some time; they may also occur in hybrid cases where a seemingly defunct product or genre is given a brief rebirth by being reincarnated in terms of a new technology.

Clearly, this is not a place for equilibrium analysis of the orthodox kind in which all that consumers are adjusting to are relative price changes and changes in their life-cycle stage that affect what they wish to consume. We need to understand how consumers cope with the problem of choice in the face of such changes, and how their preferences change endogenously. ${ }^{1}$ A better understanding

\footnotetext{
${ }^{1}$ See Bowles (1998), Witt (2001), Metcalfe (2001), Earl and Potts (2004).
} 
of the conditions under which novel goods emerge and how they are disseminated will have significant consequence for modeling macroeconomic growth. Central issues here - as with any evolutionary analysis — are the way and rate at which novel goods emerge and are adapted into the system (Dopfer et al. 2004, Witt 2003).

If we add to the ingredients the fact that many of the goods that consumers can and do buy are very long-lived, then the challenges that the changing possibility set present become all the more significant. Obsolete knowledge makes errors likely, and once errors have been made in respect of durable items their consequences may be long-lived. Fashion may be frivolous in its drivers, but it may be durable in its consequence. Set against this backdrop, fashion appears problematic: we move from considering the scope for, and consequences of, individuals making costly errors to the possibility of people en masse making choices that they will later view with considerable embarrassment.

The transitory popularity of products in the market place could, of course, simply be a reflection of a combination of their durability and functionality. ${ }^{2}$ Take, for example, DVD players and digital cameras. They were launched and people bought them en masse because they liked their enhanced functionality compared with VCRs and film-based cameras. Within a matter of years demand for them will tend to fall back to levels that reflect replacement needs (reliable designs may last 20 years or more) and growth associated with demographic change.

In such cases, economists might be concerned about coordination problems associated with mass adoption insofar as production involved investment in assets that could not be used for the production of other things: a more gradual adoption profile would permit demand to be satisfied with less investment. But, otherwise, economists would not be particularly concerned: consumers will pay more than they would have had to do if adoption were more gradual, but their willingness to pay must reflect the value of the new product to

\footnotetext{
${ }^{2}$ Improved functionality can entail both better performance on familiar dimensions, as emphasized by Lancaster (1966) or features never before offered: see Bianchi (2002).
} 
them. Also, firms are often able to smooth out adoption spikes to some degree via price discrimination strategies. In the case of DVD players and digital cameras, the asset specificity issue may not be very significant, as much of the investment will be reused in next-generation products that offer even better performance. Moreover, the earlier generation products will tend to get reallocated within the household: a household's first DVD player will probably get hooked up to a bedroom TV when a DVD recorder is bought, while a 3-megapixel camera might be given to a child when the parents invest in a digital SLR camera, and so on. Such examples, though not at odds with our definition of fashion, would normally tend to be placed under the heading of 'product life cycle economics' rather than fashion, for they have a clear rational choice basis in terms of functionality.

The spikes in demand that seem to represent more cause for concern have a rather different form: these are cases where the product is not adopted for the long term and is abandoned long before it, or the specific assets required for its production, are worn out. Here, the demand spikes are not driven by functionality but by style and social considerations. Whereas one can defend in terms of consumer time preference the tendency of firms to launch products that they fully expect to render obsolete once they have worked out how to make even better ones, it seems much harder to defend attempts of firms in fashion-dominated industries to induce obsolescence in terms of style. A superseded computer that is no longer being used because it cannot make use of broadband Internet access carries quite different connotations from a wardrobe stuffed with last year's clothing still in as-new condition but not worn purely because it is now an embarrassment to wear.

If fashion cycles involve waste, an ecological economist will naturally be concerned about them. But they ought to be of great interest to any economist who professes faith in market processes as means of enabling participants in the economy to get the most out of their resources. Within modern microeconomics, however, the theory of fashion has a curious but definite pariah status. It deals with phenomena that are too ephemeral and bourgeois for serious micro-economic theorists to touch, and that are seemingly irrelevant for macro-economists to use 
as an explanatory variable in equations that aim to pin down the causes of growth. In short, fashion is a topic that to mainstream economists seems a bit too much like sociology or cultural studies, or worse, to warrant serious attention. Fashion is irrelevance multiplied by pretension, and therefore not a serious object of study.

For the Austrians, fashion poses a particular challenge in relation to the social role of the entrepreneur. Within any fashion cycle, one can clearly see Kirznerian entrepreneurs making profits by being alert to potential or imminent spikes in demand or arbitraging between markets in which the timing of demand spikes differs. However, if, with the assistance of further entrepreneurial input, consumers keep turning their backs to the products on which the entrepreneurs have helped them spend their money, one must start questioning whether entrepreneurs in fashion-dominated sectors are performing a socially desirable function.

To argue that entrepreneurs in these sectors are helping to serve a useful role rather than acting in a way that leads to more resources being wasted, either of two conditions needs to apply:

(a) Consumers anticipate that their taste for the product will have a shorter life than the product itself and nonetheless still find it worth buying despite being aware that if they then dispose of it they will make a capital loss on a scale far greater than one that merely reflected its physical depreciation; or

(b) Despite consumers over-estimating the consumption benefits they derive from fashion goods, these losses are at least offset by social benefits that emerge as externalities of fashion cycles.

In this paper, we focus on these two conditions and argue that fashion is integral to economic growth. Just as certain market dynamics are responsible for stimulating the (re)organization of production techniques of firms, so, too, market dynamics can be thought of as stimulating the (re)organization of consumer capabilities, which have important implications for understanding the nature and direction of economic evolution. 
We argue that fashion is a mechanism for periodically liquidating elements of consumer lifestyles in a world where there is a continual flow of novel consumer goods. Changes in fashion entail the mass updating of durable goods that works to control and accelerate the depreciation of existing goods, thereby lowering the mass adoption costs of new goods into consumers' lifestyles. These adjustment costs are spread independently of whether consumers made good choices or bad choices in the previous rounds and they mitigate the effects of consumer mistakes. Fashion is to consumer theory in an evolving economic system what the liquidationist thesis of structural cleansing is to macroeconomics, under those same dynamic conditions (e.g. Caballero and Hammour 1994). ${ }^{3}$ Our proposed evolutionary theory of fashion turns the standard view of fashion in microeconomics and consumer theory on its head. Instead of viewing fashion as a profligate bourgeois indulgence, we argue that it is an essential mechanism in the economic evolution of a market-capitalist system.

\section{OLD-SCHOOL FASHION VERSUS A FOCUS ON NOVELTY}

The literature on fashion really begins with a remarkable paper by Caroline Foley (1893), but most modern articles in economics that link fashion and economic theory take Thorstein Veblen as the defining the state of the art. Veblen, typical of high-powered intellectual outsiders, was very much down on fashion. Indeed, The Theory of the Leisure Class (1899) reads like an analysis of a virulent social pathology. The centerpiece of Veblenian microeconomics is the theory of conspicuous consumption, which seeks to explain changing consumption patterns from the agent's basic desire for social status. Fashion is in this sense a kind of higher-order consumption, driven not by innate utility, but by its effects on other agents. According to Veblen, agents value and choose goods for status competition by emulating the tastes of other individuals situated at higher points in the social hierarchy. Where one is situated in the social hierarchy is decided by

\footnotetext{
${ }^{3}$ The liquidationist thesis, first advanced by Friedrich Hayek, Joseph Schumpeter and Lionel Robbins, holds that far from being an unmitigated bad, recessions are actually beneficial to the economy in that the low real prices of factors and resistance to change make them effective periods of 'structural cleansing' in a macroeconomy.
} 
income but, according to Veblen's analysis of late-nineteenth century American nouveaux riches, income alone does not equate to status. Key to transforming wealth into status is the social performance of the individual in terms of conspicuous consumption. Status derives from the judgments that other members of society make of an individual's position in society. For this position to be established there must be a display of wealth, i.e. conspicuous consumption. As the lower classes imitate the higher classes, the higher classes must come up with more conspicuous and wasteful ways to display their wealth. As such, Veblen viewed fashion as symptomatic of the inherent instability of the market-capitalist system.

Veblen's disapproving view of fashion runs into trouble as soon as we try to reconcile his idea of conspicuous with Lancaster's (1966) view that the demand for novelty can also be understood in terms of the consumer search for potential improvement in a commodity's functional properties. For improved functionality of products to be saleable to status-hungry consumers, the fact that they are consuming the latest generation of products must be conspicuous, even if their improved functionality is 'under the skin'. Otherwise, the status-seekers' expenditure will tend to go to products that are more cost-effective at signaling that one can afford the latest generation. Hence firms dominated by engineers who are desperate to compete by adding improved functionality need also to spend on re-skinning their products even if there is no functional need to do so.

For example, adding safety features to cars is an 'under-the-skin' activity. Clearly, manufacturers can spend on advertising such additions and in the early days of anti-lock braking systems and airbags being fitted to mass- market products they posted exterior signs such as rear badges that proclaimed ABS and door pillar signs that indicated (to those who knew the jargon) the presence of an airbag with the initials SRS. However, much more conspicuous cosmetic changes such as new lights, bumpers, wheels and trim garnishing may be far better effective ways of ensuring customers will buy vehicles with enhanced safety features - if indeed firms find it profitable to add the latter rather than just concentrating on the former. Note, too, that in this case, the kind of safety 
engineering that it will pay to incorporate may be affected by the extent to which it can be brought to the surface with a recognizable symbol. We are thus not at all surprised to recall that the first Australian cars to be fitted with ABS and airbags, and their accompanying badges, in the mid 1990s continued to score poorly in crash-testing despite being sold with a new emphasis on safety, because their passenger compartments still crumpled badly.

A decade after Lancaster's attempt to get economists to understand the process of change in the technology of consumption, Tibor Scitovsky (1976) made some progress in understanding the economic consequences of consumer demand for novelty. Scitovsky relied on previous studies in neuro-psychology that postulated that novel experiences stimulate changes in a person's arousal levels that, if in the right direction, lead to the sensation of pleasure. Scitovsky argued that in reaching historically high levels of comfort in their lives, modern consumers paradoxically decrease their levels of pleasure, which derive from changes in comfort levels. The search for stimulation is the search for novelty. Fashion is the touchstone of social novelty. Thus, consumers demand novelty to attain utility and fashion becomes quasi-rational. This argument, together with that of Lancaster, provides a basis on which fashion trends can be understood as the coordinated introduction of novelty into society.

It is this coordination-focused view that we think makes sense of the nature of fashion in an economic system in terms of the evolutionary dynamics of growth which are driven by the novel consumer good and the status-seeking behaviour of agents who consume goods socially. If we can understand consumers demanding novelty for the sake of arousal on the individual level, then it is simple to see how status competition or the use of fashion goods more broadly as tools social communication works in the context of gaining the attention of other members of society through consuming new items whose very novelty makes them attention arousing. As such, they invite onlookers to make judgments about the quality of choice that the status-seeker has made and hence about the status to which the status-seeker is due. This is much more in keeping with the anthropological analysis of consumption proposed by Douglas and 
Isherwood (1978), which gives a much broader view of its social side than Veblen offers: people consume to communicate, and there is much more to communicate by being up with the fashions than merely one's income or wealth. If the way that we adapt to new fashions signals something about our competences and how we see the world, it thereby help social coordination.

From Veblen's standpoint, the concern of consumers with fashion is a social phenomenon. The fashion-conscious consumer is demanding a social good, namely status, which is the 'dominant feature in the scheme of life' (Veblen 1899) and fashion would not exist if there were no one to impress. From Scitovsky's standpoint, by contrast, fashion is an artifact of the individual's demand for novelty; his argument does not ultimately depend on the existence of society, but rather on the fleeting nature of the individual's attention and the satisfaction of desire for stimulation in the form of novelty and the new stimulus and relational structures this brings. Fashion, in this view, is all about satisfying one's curiosity and seeking stimulating experiences. From this argument we understand why ultimately consumption items must be replaced, given the intrinsically fleeting nature of novelty. In both cases what is demanded, produced and exchanged is attention or stimulus.

Combining these two theories permits an understanding of how one can view consumption decisions as investment decisions without necessarily focusing upon the physical durability of the things which consumers buy. As with the purchase of consumer durables, expenditure on services and non-durable goods (for example, fitness club membership or meals in a particular restaurant, respectively) may be undertaken as an investment in building one's social standing. Each of these kinds of spending involves risk because fashion goods are what Nelson (1970) would label as 'experience goods': novel aspects of utilityyielding properties cannot be assessed in advance via search, while the social response to an act of consumption can only be conjectured at the time of purchase. The possibility of vicarious learning from the experimentation of others with novel products means there is no need for a Veblenian or anthropological 
perspective on consumption for it to have a significant social side in a world in which consumption possibilities constantly change.

Now, if fashion consumption is done for both individual and social reasons, then the obvious question that follows is about how these two distinct motivations interact to produce aggregate fashion consumption patterns. And this, we argue, requires a theory of how consumers strategically manage their consumption in a turbulent, changing and uncertain environment. Understanding a class of consumption decisions as investment decisions is one thing, but analyzing the environment and the fluctuating determinants of these decisions is something altogether different.

\section{CONSUMPTION COMPLEMENTARITIES AND MISTAKES}

Evolutionary economists argue that the growth of knowledge drives the growth of economic systems (Loasby 1999). Choice is not so much a function of preferences, but a function of rules and knowledge, of which preferences are a subset. The importance of this distinction is that rules and knowledge, unlike the orthodox idea of preferences, are fallible. Thus the basic problem for the consumer in an evolving economic system is the problem of knowing and learning what to want (Earl and Potts 2004) and then dealing with mistakes along the way.

This is not as trivial a problem as it is usually perceived to be in standard micro theory, where consumers want what satisfies their preferences, end of story. From the evolutionary perspective, the 'what to want' problem involves more than knowing (or learning) what one's preferences are; it also entails the strategic coordination of one's wants with those of other agents, and of not making mistakes in doing so-much in the same way that, as Richardson (1960/1990) emphasizes, firms need to coordinate their investment decisions. Showing up at a cocktail party in an identical dress to someone else can be every bit as embarrassing to two women as the simultaneous proliferation of major investments in capacity to produce a particular good or service can be to the firms who have made the investments, oblivious of each other's plan. In both contexts, 
there is more to the decisions than being alert to an opportunity; one must also be able to gauge the likelihood of others being alert to it and able to act on their alertness.

Knowledge influences both consumers' lifestyle choices and producers' production decisions. From continually facing new situations, agents, firms and societies learn and hence their knowledge base continually changes, which in turn changes the way they act, produce, consume and organize in the future. Modern evolutionary economics is thus especially focused on studying how new knowledge affects agents, and the system within which they act (Dopfer et al 2004). In its history, there has been a conscious effort to build an abstract model that can rigorously identify the path through which new elements of knowledge are discovered, selected and adopted by agents, firms and institutions (Dosi 1982, Nelson and Winter 1982). The evolutionary theory of consumption focuses on how the demand side evolves. If we understand consumers in a continuous process of 'learning to consume' (Witt 2001), then an evolutionary theory of consumption must seek to incorporate: (1) the selection of problems in respect of which knowledge production (learning) occurs; (2) the behaviour of learning and the complementarities between opportunities; and (3) the management of consumer capital in the face of a turbulent and changing consumption environment to which the consumer's capital is utilized.

A start to applying this alternative view of consumer behavior was made by Earl (1986), with his conception of a consumer lifestyle. A consumer lifestyle refers to the way in which the commodities that are inputs into a coherent consumption set (a lifestyle) are connected together as 'viscous collections of procedures for dealing with fluid situations in which ambiguity is the order of the day' (Earl 1986: 4). Accordingly, consumption behaviour involves more than simply working out alternative choices and picking the optimal option; it involves navigating a web of ever-changing complementarity. Consumption choices are a function of many complex forces, such as social identity in an evolving and turbulent world filled with ever-present uncertainty and the live possibility of costly mistakes: 'If opportunities are not to be thrown needlessly away, the 
consumer must be a skilled speculator and strategist' (Earl 1986: 1). Given this need for strategy, rational consumers structure their consumption behaviour around a set of priorities and goals. Such strategic behavior helps the consumer to incorporate surprise and anticipate the unexpected, as well as to cope with the inevitable interdependencies that exist among choices. The set of rules the consumer uses to coordinate complementarities is his or her lifestyle (the analogue of productive competence in the theory of the firm). Connections between durable goods are specific structures of complementarity, into which new goods may or may not fit. Thus, consumption sets can be modular, in that one consumption activity cannot simply be substituted for another, but instead the activity may be embedded within a greater consumption strategy that adds up to a consumer lifestyle, as a coherent pattern of connected activities and consumption goods. Insofar as consumers' lifestyles are based upon decision rules that involve checklists or priority systems to determine whether products fit into their systems, the lifestyle notion leads naturally to specifications in terms of lexicographic orderings instead of utility functions (see Earl 1986).

It is important to note that with this focus on the evolution of knowledge, the primary economic problem no longer concerns consumers spending a constrained amount of income on a range of commodities. Rather, it is one of consumers spending a constrained amount of attention on a range of things that offer to change the consumer's knowledge base in one way or another. Even with an unlimited amount of wealth to spend on an unlimited amount of goods, economic agents would still face the opportunity cost problem of deciding what pleasures to pursue, and for how long (Linder 1970, Steedman 2001). The opportunity cost of consumption, and the significance of novelty in dealing with it, would be clear to anyone with a substantial collection of recorded music: each new item stands as a barrier to the consumption of existing items in the collection, so the former will need to offer more novelty than remains to be gleaned from the latter by repeated consumption.

A closely related idea is the concept of bounded rationality, as first conceived by Herbert Simon, which basically states that because agents have a 
limited amount of reasoning power, decisions incur 'energy cost' (Loasby 2001). If it is cognitively costly to make accurate decisions, then any conception of the consumer perfectly optimizing decisions would require an infinite amount of time and energy. This simply reflects the extension of the fundamental law of scarcity to thought processes. It is impossible knowingly to make an optimal decision in a changing environment, and if particular consumption decisions are perceived to be less important, then less thought will be given to them. Life is a succession of disrupted states of consciousness in which the apparent importance of problems that come to our attention induces corresponding amounts of effort towards solving them or, if they represent a source of cognitive dissonance with drastic implications and little prospect of resolution, justifying turning one's gaze elsewhere or denying that they exist (Earl and Wicklund 1999).

From this perspective, it is perfectly reasonable to argue that rational economic agents in an evolving economic system will sometimes make mistakes that result in actual utility derived being less than expected utility. ${ }^{4}$ Making mistakes is inherent in fashion consumption as portrayed in the writings of both Veblen and Scitovsky. For Veblen, purchasing fashionable goods is as much for the satisfaction of other people's preferences as for one's own, since the utility one derives from fashion consumption depends on the approval of others. This is an inherent set up for making mistakes if ever there was one. For Scitovsky, fashion consumption is inherently risky, since one can never tell a priori how long an item will provide personal stimulation. If one did have perfect knowledge of a good, it could by definition no longer provide stimulation since, essentially, the demand for novelty is a demand for the unknown. In other words, consumer choice in a complex evolving world is fraught with difficulty. Stability and coherence consists of making connections between how goods fit together, both with each other, and with the social and cultural context of consumption. Mistakes will inevitably be made even by the most rational of consumers, so it becomes important for consumers to develop ways of ensuring that the mistakes that they

\footnotetext{
${ }^{4}$ Note that mistakes may also be positive, i.e. accidentally acquiring more utility than anticipated, but these do not really pose problems for agents and the economy.
} 
make do not unduly sour their experience of life in the long term and, above all, are not personally catastrophic.

The problem, then, with the old-school literature on fashion is that it was essentially drawn with respect to a static economic background (intermittent not continuous novelty) and without due consequence to the difficulties of and scope for error when choosing goods and services about which one has little experience and therefore bounded rationality.

A boundedly rational agent in a consumption environment that is constantly changing will inevitably make mistakes. Without some mechanism to periodically liquidate these mistakes, a consumer lifestyle will begin to degrade in its social capital until it reaches some threshold of social dysfunction that so passes it, along with its agent, into the realm of being unfashionable and no longer socially observed. That might suit the agent just fine, or it might not: de gustibus. The broader point is to consider the effect this has on both the course corrections of a consumer lifestyle and on the uptake of new technologies into the economy and therefore the sources of economic growth.

In an open evolving market economy, there are always new goods and services contesting the markets, so the consumption possibility set is constantly changing, via both entry and exit. This presents the consumer not just with a series of marginal choices (e.g. a new breakfast cereal), but also the possibilities of more radical change in systems of consumption possibilities (i.e. components of a lifestyle) or, even, the chance to make what is for them a revolutionary switch of lifestyle (e.g. move from the city to live by the beach and work remotely via the Internet). But marginal changes to substitute one good for another are always easier than changes to blocks of connected choices. The risk is that new goods and services may only make sense when adopted as a bundle, and may never be able to penetrate certain locked-in consumption patterns.

In an evolving economy, something must induce agents to revise and update their consumption sets in ways that still leave room for them to learn. Without such an institution, consumers are subject of overspecialization, and their consumption strategies become increasingly inflexible. They risk ending up rather 
like people with an obsessive-compulsive disorder (Earl 1986: 164-6) and, as often happens with elderly consumers, becoming detached from modern life, increasingly fearful of venturing out into the world and trying anything new. One way in which markets might promote dynamically efficient behaviour by consumers is if they incorporate some kind of mechanism that forces consumers periodically to re-orientate their learning processes onto different fields (as a kind of positive externality). Schumpeter first suggested this was achieved by the existence of entrepreneurs: 'new commodities or new qualities or new quantities of commodities are forced upon the public by initiative of entrepreneurs is a fact of common experience' (Schumpeter 1928: 379).

Whilst followers of Schumpeter long have recognized the central function of new goods as a way of evolving the economy, few have really questioned where the demand for novelty originates, and whether its strength changes over time. Intuitively, for the individual consumer, the demand for novelty is a hazardous want. Not only is there the potential for making mistakes as mentioned earlier, but transaction costs are involved in reconfiguring consumption strategies, and there is far more certainty in 'sticking to what one knows'. These costs may derive from a number of sources; anything that hinders deviation and promotes conformity is accountable in this matter. Also nothing is said about when the time is right for people to adopt innovations rather than stick to their old strategies. The demand for novelty amongst consumers acts as the essential enabling force that allows innovating entrepreneurs, as creators of novelty, to be successful. In order for consumers to invest in the construction of consumption capital that is relevant to their consumption environments, something must exist to regulate these forces.

\section{AN EVOLUTIONARY THEORY OF FASHION \& WELFARE}

What we argue here is that the introduction of a novel fashion trend into the agent's environment acts as a potential trigger for consumers to revaluate their consumption strategies in the face of this novel stimulus. The consumption strategies that they adopt in response to this novel stimulus turn into new habits. As the fashion trend becomes more normalized, novelty dissipates. Eventually a 
point is attained where novelty has dissipated to the extent where a newer stimulus is comparatively novel enough and hence attention arresting for it to be able to force consumers again to re-orientate their strategies. If existing strategies of some consumers are still relatively novel to the extent that it is not worth the transaction cost of recalibrating their strategies to new the stimulus, then novelty will not be adopted by them. It is this decisive occupation of the consumer's existing attention resources that distinguishes between whether a novel stimulus is a potential or an actualized trigger for lifestyle restructuring.

From this framework, we can also understand that the degree of lifestyle complexity is linked to the rate at which the lifestyle is updated. If consumers choose a lifestyle which presents them with a relatively large number of problems, then over time they will have much less attention to dedicate to novel solutions to any particular problem than is available to those who choose much simpler lifestyles. Given this, we would expect much more herd-like behaviour to be displayed by those with complex lifestyles. Such consumers may have only small areas in which they can develop the expertise to choose for themselves. In principle, they may serve in those areas as trendsetters for their peers, whilst following the latter in other respects. However, in such situations there would be a problem of the overall coordination of the fashionable fit of different but complementary elements of the evolving lifestyle, particularly if specialists in some consumption areas differed in the signals they presented to their peers about 'the way to go'. Therefore, in practice in such cases, the busy consumers might be expected to delegate to an outside authority with professional expertise the task of ruling on what fitted together.

Complex, busy lifestyles seem incompatible with long fashion cycles because of the rapid convergence of behaviour via the use of externally supplied decision rules. By contrast, 'classic' styles of consumption that only evolve slowly and are commonly thought of as refined, would seem to be the prerogative of those whose wealth has given them a longstanding ability to consume at leisure. Such 'old money' consumers are rich enough to keep many problems at bay_often by following long established social rules—and, having not just 
'arrived' (unlike the nouveaux riches), they have built up the experience to know how to choose in those areas where the absence of rigid social codes gives them that freedom. Their lack of experience outside their narrow range of deep expertise imparts a profoundly conservative bias to their choices, and their connoisseurship is such that relatively small changes in products that make up their lifestyles will be sufficient to attract their attention. Anything with a particular category that is wildly different from their view of the norm will not capture their attention as it will not fit their classificatory pigeonholes (Hayek 1952).

Fashion cycles and the consumer's taste for novelty appear to play a very important—not wasteful—role in encouraging flexibility and experimentation in consumer strategies and thereby promoting the development of consumer knowledge and experience. Competition for social standing is not based merely upon displays of how much money one can afford to burn on a particular kind of consumption but also on the ability to display skill in placing the right kinds of fashion bets and not ending up as a 'fashion victim' by failing to select neither a fashion rule that is also selected by the vast majority around the same time, nor a strategy whose minority status is regarded as a sign of one being 'hip' in Holbrook's (1995: 319-62) sense of displaying expertise and insight that is ahead of the field.

As the impact of the television series Sex in the City on women's fashion has demonstrated, such rules may embrace both the set of products to purchase and rules for the combinations in which products are consumed. Seen thus, the fashion-leading consumer has many of the capabilities of an entrepreneur who is alert to gaps in markets and to new opportunities for constructing connections (cf. Earl, 2003). This point has an important implication: the consumer-producer duality that has been a feature of much economics since John Stuart Mill separated demand and supply may be misleading, for entrepreneurs are also consumers. If consumers were predominantly lethargic dullards, growth would be limited not merely due to a lack of interest in new things but also due to a lack of new products in which to be interested. As an anonymous referee for this paper 
pointed out 'Creative and energetic people will express those qualities on both sides of the market, for those two sides are analytical constructions that pertain to the same people'.

This implies a new slant on Scitovsky's The Joyless Economy: those societies that focus on comfort rather than risk-taking pleasure should be expected to have relatively low growth rates due to low levels of entrepreneurial creativity. However, caution is needed here, for comfort-seeking societies may be much more receptive to products developed at home, than to boldly innovative products from more pleasure-focused economies and patterns of trade would therefore not necessarily favour the latter. The former societies could still have fashion cycles, but they would tend to be rather routine, perhaps exemplified by minor but visible tinkering with car designs to signify a new model year.

When a fashion cycle comes to an end, those who placed unfortunate bets are put back on a more nearly equal footing with those who succeeded in avoiding being seen, that time around, as fashion victims. For example, if all trousers fall out of fashion in favour of skirts, then it no longer matters that one chose the 'wrong trousers' when they were in fashion; the issue now is whether one can make a competent choice of skirt in the eyes of one's reference group. To be fashionable now, both fashion victor and fashion victim must incur the costs of tooling up for the novel fashion mode. Fashion cycles also play a major redistributing role in society that mitigates their seemingly wasteful 'throw away' aspect. The accelerated depreciation of fashion goods enables them to be enjoyed secondhand by consumer subcultures whose members could not hope to purchase them if their early rates of monetary depreciation accurately reflected their physical depreciation.

5 THE IMPACT OF FASHION CYCLES ON AGGREGATE DEMAND AND CREATIVITY

The demand-triggering role of changes in fashion mitigates a problem for affluent economies that was recognized by Fisher (1935) and Reddaway (1937): there is a 
clash between progress and security when rising incomes open up new consumption possibilities and, with them, new risks. Consumption becomes much more like business investment when unfamiliar new (or previously unaffordable) products are involved, as it does when it has a social dimension and reactions of onlookers cannot be taken for granted. The key problem for sustaining economic growth in affluent economies is that if income is available for discretionary spending, by definition it does not have to be spent. As economic psychologist George Katona (1960) emphasized, the affluent consumer may have the ability to spend (and modern consumers have much more access to credit than they did when Katona was writing), but demand may dry up if they lack the will to spend.

Clearly, concerns about the security of income streams that are necessary to service debt or save up for retirement may make consumers unwilling to spend, but so too may seemingly overwhelming tasks of choosing the right product in a functional or social sense. If one does not have to buy something, the problem of choosing what to buy can simply be left in the 'too hard basket' for now, but in leaving it there, one is taking away someone else's income flow and inducement to invest. In terms of our analysis, the forces of fashion can intervene, via the pressure of social competition, to overcome such weakness of will and help to keep the economy closer to its potential growth trajectory. ${ }^{5}$

At the micro level, fashion cycles are inherently disruptive and attempts by firms to insure against them by diversification carry costs in terms of foregone economies of scope (Kay, 1997). However, at this level, there may be lessons to be learnt from research on the effects of investment spikes at the macroeconomic level, such as those associated with tendencies of firms to invest in plant investments in bursts rather than in small adjustments of capital stock as the neoclassical theory suggests.

The theme of lumpy replacement cycles has become increasingly popular amongst macroeconomists who face the task of explaining volatile investment

\footnotetext{
${ }^{5}$ Note that we are not saying that the forces of fashion assure maximum possible growth and full employment. The case of Japan is a reminder that an economy can be very focused on fashion and novelty and yet still have high rates of saving and suffer from economic stagnation, but its stagnation would have been far worse without fashion as a driving force, both in terms of domestic demand and in terms of the benefits derived from the export of innovative products.
} 
patterns amongst firms (Cooley et al. 1997, Cooper et al. 1999). From this approach a number of conjectures have been made about a link between macroeconomic fluctuations and investment spikes. Cooper and Haltiwanger first proposed that times of economic downturn are the best times to replace capital stock. They contend that 'Machine replacement is most likely to occur during downturns where the resource cost replacement is lower (due to low demand and/or high value of leisure) and just prior to upturns where the benefits of replacements are higher' (Cooper and Haltiwanger 1990: 34). Indeed, there have been many documented cases where recessions caused by weakening demand, have liquidated all but the most technologically advanced firms. Similarly, Caballero and Hammour (1994) observe that job destruction is much more responsive than job creation to business cycles, which leads them to argue that recessions are a time of 'cleansing' when outdated or unprofitable techniques and products are pruned out of the system. ${ }^{6}$ Potts (2004) has argued that we might view asset price bubbles in the same way. An asset bubble is a further variant on the liquidationist thesis, arguing that the low cost of finance and the tolerance for mistakes that accrues during a bubble increases the rate of novelty generation and diffusion. This surge of liquidity and experimentation fuels investor (and consumer) demand, at the same time promotes the restructuring of the economic system.

The micro-level counterpart of this line of thinking involves applying Burton Klein's (1977) analysis of the link between product lifecycles and economic growth to the case of fashion. Klein's key theme is that uncertainty about what will become the dominant standard for a product genre is good for productivity growth, and that productivity growth tends to slow down once a standard has emerged and production has become concentrated in the hands of the firms who survived because they worked out the least-cost way of making products in terms of this standard.

\footnotetext{
${ }^{6}$ In a later study of US manufacturing data, Caballero and Hammour (1999) found evidence for a 'reverseliquidationist' position, which held that recessions can be associated with a 'chill' in the restructuring process, rather than increased 'turbulence'. Thus an increased period of liquidation does not necessarily lead to a increased period of restructuring. How well these two are connected will depend on the institutional environment in which the firms operate (Caballero and Hammour 2000).
} 
The crucial driving force of innovation are the rich pickings that await those who place their bets on the winning standard and work out how to make it win by solving technological problems. Once the big challenges have been dealt with and it is clear that the winning standard of, say, the motor car involves internal combustion engines rather than steam or electric power, steering wheels rather than tillers, and so on, Klein suggests that the survivors will recognize that they are each big enough to get the capabilities and funds to replicate any major changes their rivals venture. Competition then becomes much less technologically aggressive and changes tend to be more marginal rather than revolutionary in nature. Major changes will thus tend to be made only if originated by outsiders.

If applied to the context of fashion cycles, Klein's argument must be cast more in terms of uncertainty about aesthetic issues than technological ones. But in this context it involves both producers and consumers. When a product goes out of fashion, its producers and past consumers are forced into problem-solving mode. Thus although the liquidation of some of their assets is costly to them, the process of dealing with this setback is likely to result in them emerging with enhanced knowledge. Furthermore, since the end of one fashion cycle is not the beginning of a clearly defined new fashion but a time for experimentation within a new genre, there is everything to play for. It therefore pays to be bold and creative, whether as a consumer or as a producer, given the possibility of becoming a leader. Even those who lose their jobs in firms whose products have fallen out of fashion without being replaced by something else that is successful may emerge from the experience wiser and more prosperous and/or content: to find a new job may involve relocation and retraining, and generally getting out of the rut they were in.

The revolutionary change in the popular music market that took place in the second half of the 1970s is an excellent example of this process. It involved the displacement of progressive rock, based on performer virtuosity and elaborate stage design, by the 'new wave' of much simpler music such as punk rock. Suddenly, major record companies found their established acts were not selling and instead consumers were buying music by new performers that was being 
released by small, independent record companies. This was also a time of great opportunities for performers with no track records in the music industry.

Record companies and consumers alike thus faced an explosion of new acts offering creative new sounds and images, but it was far from clear to either group where they should invest if they were to avoid financial and/or social embarrassment: would it be wise to invest money in the output of a band such as The Sex Pistols whose members were trying to appeal by breaking all the established rules, or would it better to invest in music that was less pompous and arty than that of bands such as Yes or Emerson, Lake and Palmer but was at least being produced by musicians who had some skill in playing their instruments and writing well-crafted, catchy songs? Further uncertainty was caused by technological change that resulted in bands using cheap synthesizer keyboards starting to challenge those based on guitars. The upheaval also forced the former progressive rock giants to experiment and reinvent themselves, with the result that some bounced back several years later with huge success and a wider audience than before-without The Sex Pistols' 'Anarchy in the UK', Yes might never have come up with 'Owner of a Lonely Heart'. And in the midst of all this, the major record companies learnt a lot about just how lax they had been in containing recording costs whilst progressive rock epics were being hatched.

\section{CONCLUSION}

Where the standard view of fashion in microeconomics and consumer theory views fashion as a profligate indulgence, we have argued that it plays a more positive role in stirring consumers into actions from which their pools of knowledge and range of experience may grow. Just as an increase in the strength of competition may prompt decision-makers to explore ways of increasing productivity, so a change in relative competitive strength between statusconscious consumers may force them to rethink their choices. Just as firms in featherbedded markets may fail to develop new knowledge, so consumers who opt out of social competition and take the 'quiet life' may fail to develop their ranges of experience and capabilities. Such a lifestyle may appeal to older 
consumers: they have established who they are in the social order and, with fewer years of life remaining, they have less of an incentive to take risks associated with experimentation to acquire new capabilities as consumers. Not so the young, for whom there are higher pay-offs to being 'hip' and acquiring a reputation of being ahead of the pack or, at least, to know what is fashionable.

Mistakes are inevitable in the process of social competition. Sometimes we buy consumer goods that just don't fit into our lifestyles, things that just don't connect or enable us to connect socially: the wrong trousers, or the wrong loungesuite, or cell-phone, or club membership, or car, and indeed any durable good in some measure. Development in consumer lifestyles is a process of re-coordination of a complex system of consumer durables. This growth process is facilitated by periodic liquidation for exactly the same reason that macroeconomic growth is also facilitated by periodic liquidation, namely that it lowers the overall cost of transformation. Fashion is a mechanism that is a part of this process and so fashion cycles are necessary components of macroeconomic growth.

Fashion not only enforces flexibility in consumer lifestyles, but also has a positive distributional effect on consumer welfare by erasing past consumer mistakes as well as minimizing the opportunity cost of adopting novelty. Continuous economic growth requires consumers to have a continuous will to buy, learn, and take risks. Risk-taking behavior inevitably causes mistakes, which are a necessary byproduct of economic growth. What is needed, therefore, is a mechanism to erase consumer mistakes in order to regenerate the incentive for them to continue learning. The modern social phenomena of fashion enables economic growth by providing consumers the twin incentive of both abandoning old fashion rules and adopting new rules through: (a) periodically liquidating dated fashion goods and their related mistakes, and (b) providing alternative goods that, thanks to standardization, cater for the varying risk preferences of consumers. Fashion trends can thus be understood as learning trajectories by reorientating consumer attention into new areas of learning. Through the working of social pressure, they periodically provide a fresh and self-regulated impetus for consumer learning. Fashion cycles periodically loosen the constraints that 
accumulate on the demand side and thereby facilitate the process of economic growth and personal development.

References

Bianchi, M. (2002). Novelty, Preferences, and Fashion: When Goods are Unsettling. Journal of Economic Behavior \& Organization, 47: 1-18.

Bowles, S. (1998). Endogenous Preferences: The Cultural Consequences of Markets and other Economic Institutions. Journal of Economic Literature, 36: 75-111.

Caballero, R. and Hammour, M. (1994). The Cleansing Effects of Recessions. American Economic Review, 84: 1350-68.

Caballero, R. and Hammour, M. (1999). The Cost of Recessions Revisited: A Reverse-Liquidationsist View. National Bureau of Economic Research Working Paper, 00-02.

Cooley, T., Greenwood, J. and Mehmet, Y. (1997). The Replacement Problem. Journal of Monetary Economics, 40:457-99

Cooper, R. and Haltiwanger, J. (1993). The Aggregate Implications of Machine Replacement: Theory and Evidence. American Economic Review, 83: 36082.

Dopfer, K., Foster, J. and Potts, J. (2004) Micro-meso-macro. Journal of Evolutionary Economics, 14: 263-80

Dosi, G. (1982). Technological Paradigms and Technological Trajectories: A Suggested Interpretation of the Determinants and Directions of Technical Change. Research Policy, 12: 147-62.

Douglas, M. and Isherwood, B. (1978). The World of Goods: Towards an Anthropology of Consumption. New York: Basic Books.

Earl, P.E (1986). Lifestyle Economics: Consumer Behaviour in a Turbulent World. Brighton: Wheatsheaf.

Earl, P.E. (2003). The entrepreneur as a constructor of connections. In R. Koppl (ed.) Austrian Economics and Entrepreneurial Studies: Advances in Austrian Economics, 6, Oxford, JAI/Elsevier: 113-130.

Earl, P.E. and Potts, J. (2004). The market for preferences. Cambridge Journal of Economics 28, 4, 619-33.

Earl, P.E. and Wicklund, R.A. (1999). Cognitive dissonance. Pp. 81-88 in Earl, P.E. and Kemp, S. (eds) The Elgar Companion to Consumer Research and Economic Psychology. Edward Elgar: Cheltenham.

Fisher, A.G.B. (1935). The Clash of Progress and Security. London: Macmillan. Foley, C. (1893). Fashion. The Economic Journal, 3: 458-74.

Hayek, F.A. von (1952). The Sensory Order: An Inquiry into the Foundations of Theoretical Psychology. London: Routledge.

Holbrook, M.B. (1995). Consumer Research. Thousand Oaks, CA and London: Sage. 
Karni, E. and Schmeidler, D. (1990). Fixed Preferences and Changing Tastes. American Economic Review, 80:262-67.

Katona, G.A. (1960). The Powerful Consumer. New York: McGraw-Hill.

Kay, N.M. (1997). Pattern in Corporate Evolution. Oxford: Oxford University Press.

Klein, B.H (1977). Dynamic Economics. Cambridge, MA: Harvard University Press.

Lancaster, K. (1966). Change and Innovation in the Technology of Consumption. American Economic Review, 56: 14-23.

Linder, S.B. (1970). The Harried Leisure Class. New York: Columbia University Press.

Loasby, B. (1999). Knowledge, Institutions, and Evolution in Economics. London: Routledge.

Loasby, B. (2001). Cognition, imagination and institutions in demand creation. Journal of Evolutionary Economics, 11: 7-21.

Nelson, P. (1970). Information and Consumer Behavior. Journal of Political Economy, 78: 311-29.

Nelson, R. and Winter, S. (1982). An Evolutionary Theory of Economic Change. Belknap Press of Harvard University Press. Cambridge, MA.

Potts, J. (2000). The New Evolutionary Microeconomics. Cheltenham: Edward Elgar.

Potts, J. (2004). Liberty Bubbles. Policy (CIS) 20: 15-21.

Redaway, W.B. (1937). Special Obstacles to Full Employment in a Wealthy Economy. Economic Journal, 47, June: 297-307

Richardson, G.B. (1960). Information and Investment. Oxford University Press, Oxford (republished, 1990).

Saviotti, P. (1996). Technological Evolution, Variety and the Economy. Cheltenham: Edward Elgar.

Scitovsky, T. (1976). The Joyless Economy: An Inquiry into Human Satisfaction and Consumer Dissatisfaction. Oxford: Oxford University Press.

Steedman, I. (2001). Consumption Takes Time. London: Routledge.

Veblen, T. (1899). The Theory of the Leisure Class. New York: Macmillan (London, Penguin, 1994).

Witt, U. (2001). Learning to Consume: A Theory of Wants and the Growth of Demand. Journal of Evolutionary Economics, 11: 23-36.

Witt U (ed) (2003). The Evolving Economy: Essays on the Evolutionary Approach to Economics. Cheltenham: Edward Elgar. 